\title{
A CONTRARREFORMA NEOLIBERAL E A TERCEIRIZAÇÃO: a precarização como regra
}

\author{
Graça Druck* (https://orcid.org/0000-0003-0363-6883) \\ Renata Dutra * * (https://orcid.org/0000-0003-0736-8556) \\ Selma Cristina Silva *** (https://orcid.org/0000-0003-0823-0137)
}

\begin{abstract}
O objetivo deste artigo é discutir os principais elementos da essência da contrarreforma trabalhista no Brasil, situando-a na atual conjuntura da realidade brasileira, no contexto do capitalismo globalizado e flexível, sob a hegemonia neoliberal. Busca-se responder as seguintes questões: i) Por que foi possível aprovar essa contrarreforma neste momento, depois de mais de 30 anos de tentativas do empresariado de pôr fim à CLT? ii) Qual a essência dessa contrarreforma? iii) Qual a relação entre terceirização e as mudanças na nova legislação? iv) Quais as principais alterações e sobre quais espaços e grupos elas incidem? v) Quais são as resistências e perspectivas manifestadas pelos mais diferentes sujeitos sociais diante da nova legislação?
\end{abstract}

PALAVRAS-CHAVE: Reforma trabalhista brasileira. Terceirização. Precarização do trabalho. Lei 13.467. Resistências.

\section{INTRODUÇÃO}

O objetivo deste artigo é discutir alguns dos elementos que constituem a reforma trabalhista no Brasil, situando-a na atual conjuntura da realidade brasileira e à luz do contexto mais geral das mudanças no trabalho e das formas de regulamentação dos direitos trabalhistas no plano global. Para tanto, busca-se indicar o quadro mais geral da situação do trabalho anterior à reforma - em que a terceirização ocupa lugar central nas últimas décadas, conformando um cenário de profunda precarização do trabalho nos mais diferentes aspectos, como o salário, as condições de trabalho, a jornada de trabalho, a saúde do trabalhador e a organização sindical

* Universidade Federal da Bahia. Faculdade de Filosofia e Ciências Humanas. Programa de Pós-graduação em Ciências Sociais. Programa de Pós-graduação em Serviço Social. Centro de Estudos e Pesquisas em Humanidades (CRH). Rua: Aristides Novis, 190, Federação. Cep: 40226-365. Salvador - Bahia - Brasil. druckg@gmail.com

** Universidade Federal da Bahia. Faculdade de Direito. Programa de Pós-Graduacão em Direito. Centro de Estudos e Pesquisas em Humanidades (CRH).

Rua da Paz, s/n. Graça. Cep: 40150-140. Salvador - Bahia Brasil. Renataqdutra@gmail.com

* * * Universidade Federal da Bahia. Faculdade de Educação. Departamento de Educação I. Centro de Estudos e Pesquisas em Humanidade (CRH).

Rua: Aristides Novis, 190, Federação. Cep: 40226-365. Salvador - Bahia - Brasil. selmacsj@gmail.com
- para buscar compreender como a "reforma trabalhista” institui a precarização como regra.

As idéias desenvolvidas e os dados analisados visam a responder às seguintes questões: i) Por que foi possível aprovar essa reforma neste momento, depois de mais de 30 anos de tentativas do empresariado e seus representantes de pôr fim à CLT? ii) Qual a essência dessa reforma? iii) Quais as principais alterações no campo do direito do trabalho? iv) Em que medida a terceirização compõe o cenário da reforma trabalhista e aprofunda suas consequências? v) Quais as resistências e perspectivas já manifestadas pelos mais diferentes sujeitos sociais diante da nova legislação e sua aplicação no caso brasileiro?

\section{POR QUE A REFORMA FOI APRO- VADA NESTE MOMENTO?}

Há pelo menos 40 anos, o capitalismo globalizado, hegemonizado pelo capital financeiro, vem transformando a economia, impondo sua lógica de curto prazo e de volatilidade a todas as demais atividades econômicas e aos 
modos de gestão do trabalho. A acumulação flexível (Harvey, 1992), que se afirma por meio da ruptura com o modelo fordista, engendra outros modos de trabalho e de vida, pautados na flexibilização e precarização do trabalho. Tal fenômeno impulsiona e se alimenta de uma nova configuração do Estado.

Nesse cenário, forja-se o aprofundamento da submissão e a conformação dos trabalhadores às novas demandas, com o amparo fundamental de uma racionalidade neoliberal (Dardot; Laval, 2016), por meio de um processo de subjetivação pautado no individualismo e na generalização da concorrência, que alcança diversos estratos sociais. O projeto econômico, político, social e ideológico que se intitula neoliberalismo se sustenta em "um novo modo de governo dos homens segundo o princípio universal da concorrência” (Dardot; Laval, 2016, p. 17), o qual tem se concretizado por meio da exploração do trabalho humano com limites cada vez mais débeis e com o amparo de um modelo de regulação propício à acumulação financeira - e, portanto, intencionalmente contrário aos paradigmas de proteção social.

Segundo Dardot e Laval (2016, p. 274275 , grifo nosso), trata-se da

[...] Mudança da concepção de ação pública, agora subordinada aos valores, prática e funcionamento da empresa privada. Um [...] Estado mais flexível, reativo, fundamentado no mercado e orientado para o consumidor. [...] que não visa apenas aumentar a eficácia e reduzir custos da ação pública; ela subverte radicalmente os fundamentos modernos da democracia, isto é, o reconhecimento de direitos sociais ao status de cidadão. [...] O que se viu foi uma 'mercadorização da instituição pública obrigada a funcionar de acordo com as regras empresariais' [...]

Assim, a reforma trabalhista brasileira se insere num paradigma global de reformas neoliberais que, desde a década de 1970, tem importado em flexibilização e crise do direito do trabalho, tal como foi concebido ao longo do século XX. As experiências internacionais que apontam nessa direção multiplicaram-se a partir da crise mundial de 2008. Na última dé- cada, foram observados processos de reformas flexibilizadoras da legislação trabalhista em países europeus (a exemplo da Espanha, que inspirou o projeto brasileiro, e da reforma mais recente na França) e também na América Latina, em países como Chile, Argentina, México, evidentemente, em contextos peculiares, que dizem respeito também à conjuntura política de cada um desses países.

A despeito das especificidades nacionais que diferenciam tais países, principalmente em relação à diversidade de seus respectivos ordenamentos jurídicos, observa-se que as "reformas trabalhistas" realizadas pautaram-se na desconstrução do sistema de proteção social, como ele era anteriormente conhecido, e no recuo da regulamentação protetiva das relações de trabalho, em favor de modelos pautados na prevalência da negociação direta entre empregadores e trabalhadores.

No caso brasileiro, a história das lutas e conquistas dos trabalhadores, que resultou na legislação trabalhista dos anos 1930 e que se consolidou com a CLT de 1943, foi fruto do que se poderia chamar de traços de uma "revolução passiva”, que, de acordo com Carlos Nelson Coutinho (2012, p. 120), se desenvolve a partir de um processo dialético em que as demandas dos subalternos são parcialmente acolhidas, sem perder de vista o objetivo de conservação da ordem por parte das classes dominantes. Nessa ótica, a modernização trabalhista não se desatrela de um movimento por meio do qual, de modo complexo, se conservam velhas estruturas.

Daí porque o conjunto normativo trabalhista sempre encontrou dificuldades em sua efetivação, havendo registros, na literatura, de seu descumprimento sistemático, conforme atestam estudos realizados no país (Filgueiras, 2012; French, 2002; Vianna, 1999) até dados mais recentes consubstanciados nos próprios relatórios do Conselho Nacional de Justiça (CNJ) sobre as principais demandas dos processos trabalhistas, que revelam que a maior parte das ações ajuizadas no país ainda tem 
por escopo prioritário o recebimento de verbas rescisórias sonegadas pelo empregador. ${ }^{1}$

No regime militar, de 1964 a 1968, foram alterados, revogados ou revitalizados 235 artigos da CLT, além da produção de legislação específica, como a lei do Fundo de Garantia por Tempo de Serviço (FGTS), que implicou, na prática, o fim da estabilidade decenal no emprego. Também são representativos da flexibilização trabalhista levada a cabo nesse período, que é marcado por significativo congelamento da massa salarial: a Lei $\mathrm{n}^{0} 4.330$, conhecida como "lei antigreve"; o Decreto que liberou a terceirização no serviço público (Decreto-Lei $\mathrm{n}^{\circ}$ 200/1967); a lei do trabalho temporário (Lei $\mathrm{n}^{\mathrm{o}}$ 6.019/1974), dentre outras. Além disso, o governo militar decretou a intervenção em 433 entidades sindicais, com a prisão, cassação e perseguição de líderes sindicais e colocando na ilegalidade representações como a União Nacional dos Estudantes (UNE) e as Ligas Camponesas (Miranda, 2016; Souto Maior, 2014).

Após a redemocratização do país nos anos 1980, um processo marcado por lutas e reorganização dos movimentos sindicais e sociais, foi promulgada a Constituição de 1988, que estabeleceu um conjunto de direitos sociais e do trabalho, bem como a reorganização da estrutura sindical com mais liberdade, retomando o fôlego da proteção trabalhista.

Entretanto, na passagem para os anos 1990, consolida-se, de forma programática, a agenda neoliberal no Brasil. Desde então, a "modernização" da CLT passa a fazer parte da agenda empresarial (a exemplo das 101 propostas da CNI) e do discurso midiático predominante (Calixto, 2013).

No Brasil, portanto, o avanço do pensamento neoliberal coincide, contraditoriamente, com o período de vigência da Constituição de 1988. Foi durante o período de vigência do

${ }^{1}$ Exemplares desse comportamento são os dados do relatório Justica em Números do Conselho Nacional de Justiça (CNJ), de 2016: 49,43\% das demandas trabalhistas, em toda a Justiça do Trabalho, decorrem do não pagamento das verbas rescisórias a que têm direito os trabalhadores demitidos; na sequência, vêm os pedidos de pagamento de horas extras registradas e não pagas pelos empresários e o reconhecimento do vínculo de emprego. documento político mais avançado em termos de proteção social e trabalhista, garantidor de uma perspectiva ampliada de cidadania, que se desenhou, no país, um conjunto significativo de reformas da legislação do trabalho, aliado ainda a reformas do Estado e a privatizações, notadamente durante o governo Fernando Henrique Cardoso (FHC), na década de 1990. Todo o período subsequente é marcado por uma série de tensionamentos quanto à regulação do trabalho, no cerne dos quais a terceirização esteve presente.

Embora seja possível afirmar que as ações do empresariado para por fim à CLT encontraram a resistência dos trabalhadores nestes últimos 30 anos, notadamente diante do insucesso das propostas de ampliação da terceirização e de prevalência do negociado sobre o legislado, suscitados durante o governo FHC, somente em 2017 foi possível aprovar uma reforma trabalhista que atende integralmente às proposições empresariais que constavam nas agendas e documentos de entidades representativas há alguns anos.

Após um período de ascensão do Partido dos Trabalhadores ao poder (2003-2015), em que houve um processo contraditório de contenção da velocidade do avanço do modelo neoliberal, conjugada com um modelo de conciliação de classes (Braga, 2012), a ruptura institucional de 2016 (Santos, 2017) possibilitou que essa agenda fosse retomada com vigor pelo Presidente Michel Temer, culminando no açodado processo legislativo de apenas três meses que levou à aprovação das Leis n ${ }^{0}$ 13.429/2017 e 13.467/2017, diplomas normativos que tratam, respectivamente, da terceirização irrestrita e do conjunto mais amplo de modificações legislativas que se denominou "reforma trabalhista".

Cabe destacar a ausência de participação do movimento sindical e da sociedade civil organizada na discussão e tramitação desses projetos, que não foram objeto sequer de emendas parlamentares. Por meio de acordo político posteriormente descumprido, o então Presidente da República se comprometeu 
a editar Medida Provisória salvaguardando as divergências mais contundentes dos parlamentares, em troca de que eles não apresentassem emendas e, assim, de que não impedissem a tramitação extraordinariamente célere que a reforma trabalhista teve. De fato, após a promulgação da Lei $\mathrm{n}^{\mathrm{o}} 13.476 / 2017$, foi editada a Medida Provisória $\mathrm{n}^{\circ}$ 808/2017, que caducou em 22/4/2018, sem conversão em lei, o que implicou a persistência da redação original da reforma trabalhista, ressalvados apenas os atos acobertados pelo curto período de vigência da mencionada medida provisória.

É importante observar, portanto, que o contexto político em que se dá a aprovação da reforma da legislação trabalhista brasileira integra um cenário de crise democrática, com déficit de representação política e avanço de agendas de interesse das elites minoritárias, o que se atrela, de modo substantivo, ao cenário neoliberal.

Rafael Valim (2017), em estudo sobre a forma jurídica do Estado sob o neoliberalismo, relaciona a ascensão desse modelo econômico com a crise das democracias e aponta para a institucionalização do Estado de Exceção. O autor destaca que, embora seja corriqueiramente descrito como um modelo político-jurídico de Estado mínimo, a característica neoliberal, em verdade, tem consistido na "impotência da política pe-

$\stackrel{2}{\overrightarrow{2}}$ rante a economia" associada a um "aumento de . sua potência sobre a sociedade", de modo que o \& mesmo Estado que se apresenta como instância fraca de decisão e formulação de políticas, sucumbindo aos interesses do mercado, se coloca como forte organismo de gestão da população e de controle social (Valim, 2017, p. 31).

i.

Assim, as idéias de Estado máximo na economia e mínimo na política conformam o paradigma neoliberal, desenhando o esvaziamento da arena pública e a desertificação do conflito - e, portanto, da política - em decisões que reverberem interesses econômicos (Valim, 2017). Para o autor, "o neoliberalismo transforma a democracia liberal em uma retórica vazia, sem correspondência com a realidade social" (Valim, 2017, p. 33), sendo, nesse am- biente de antagonismo cada vez mais evidente entre ordem democrática e neoliberalismo, que irromperiam os Estados de Exceção.

Examinando o caso brasileiro, Valim (2017) destaca o papel do Poder Judiciário no aprofundamento dessa condição, por meio da corrosão das garantias democráticas justificadas em face de interesses supostamente superiores. O autor defende que, a par da posição soberana do mercado, o caso brasileiro se definiria por uma atuação desvirtuada do Poder Judiciário a partir da eleição da "corrupção" como inimigo público, cujo combate justificaria todo e qualquer afastamento da ordem constitucional.

Some-se a isso o desvirtuamento da atuação contramajoritária do Poder Judiciário em defesa dos direitos fundamentais, sobretudo de natureza social, quando a atuação das Cortes Superiores, em alinhamento com o projeto dominante, relativiza o projeto constitucional em favor de demandas "pragmáticas" do mercado. Assim, a gravidade do caso brasileiro estaria no fato de ser o Poder Judiciário órgão que, em tese, representaria a última fronteira de defesa da ordem constitucional, exatamente o responsável por medidas que atingem todo o catálogo de direitos fundamentais (individuais, sociais e políticos), configurando aquilo que se denomina de um "processo desconstituinte" (Valim, 2017, p. 52).

É com esse grau de desmonte das instituições da democracia representativa que se presencia, no país, a uma agudização da luta de classes, protagonizada pela ação das classes dominantes, através de golpes aos direitos constitucionais que, desrespeitando a legislação em vigor, impõem mudanças legislativas tendo por objetivo deixar a classe trabalhadora à mercê do mercado e dos interesses privados. Isso é o que se observa com a rapidez das medidas, na forma de emendas constitucionais, projetos de lei e portarias encaminhadas pelo governo Temer e sua base parlamentar, a exemplo da Emenda Constitucional no 95/2016, que congelou os gastos sociais por 20 anos, da "re- 
forma trabalhista”, da reforma do ensino médio, da proposta de instituição do regime de capitalização da previdência social, da fragilização da fiscalização do combate ao trabalho análogo ao escravo, dentre outras.

Assim, a aprovação da reforma trabalhista no Brasil em 2017 se dá em um ambiente político de ascensão de um projeto político de direita, de recuo do movimento sindical e dos partidos que se afirmam politicamente como de esquerda, bem como de forte apelo do cenário de desemprego que assola o país há quase cinco anos e com amparo no discurso midiático de "modernização". Não se pode perder de vista, ainda, o silencioso papel de confrontação da jurisprudência da Justiça do Trabalho pela atual composição do Supremo Tribunal Federal (STF), por meio de um conjunto de decisões que reviam pontos já estabilizados pela justiça trabalhista, em favor de perspectivas flexibilizadoras e influenciadas pela racionalidade neoliberal, tal como aconteceu com a validação de normas coletivas sobre supressão das horas de trajeto, a autorização de quitação dos contratos de trabalho por meio de adesão ao Plano de Demissão Voluntária (PDV) e, mais recentemente, a validação da terceirização irrestrita .

Por toda essa conjuntura, trata-se de reforma que supera, em muito, o viés liberalizante que já se observara na década de 1990, seja pela amplitude das modificações propostas, seja pelo grau de ruptura com os pilares do sistema normativo anteriormente vigente. Tal processo, entretanto, encontra-se longe de ser considerado encerrado, uma vez que a ascensão de Jair Bolsonaro à Presidência em 2019 vem acompanhada de propostas de reformas ainda mais austeras, que envolvem a continuidade da desconstrução da legislação trabalhista. O Presidente eleito marcou o início do seu governo com a extinção do Ministério do Trabalho, pela primeira vez após 78 anos de sua criação, e anuncia a reforma dentro da reforma, prevendo a criação de uma "carteira de trabalho verde e amarela", a redução de custos de contratação por meio da facultatividade da contribuição patronal para o INSS e também a possibilidade de não pagamento da multa do FGTS para os trabalhadores aposentados.

Embora a primeira grande missão do governo esteja colocada em alinhamento com os interesses do capital financeiro, em torno da reforma da previdência, não se pode perder de vista que essa reforma se coloca como antecipação de uma "nova" reforma trabalhista, ou mesmo de uma radicalização da reforma já realizada em 2017.

\section{A ESSÊNCIA DA REFORMA TRABA- LHISTA}

Diante da exposição feita no tópico anterior, percebe-se que a aprovação da Lei 13.467, em julho de 2017 foi possível porque se vive numa conjuntura - internacional e nacional favorável a essa ofensiva de desmonte dos direitos sociais e trabalhistas. Tal contexto ajuda a explicar a essência dessa "reforma trabalhista”, que pode ser compreendida, analisando-se três aspectos fundamentais.

Em primeiro lugar, ela é expressão da ação classista do capital contra uma classe trabalhadora que se encontra fragilizada após um processo político complexo de ascensão de lideranças sociais ao Poder, por meio do qual as principais lideranças trabalhistas se pautaram em estratégias de negociação com o empresariado, se amoldaram aos procedimentos de institucionalidade e, após o golpe parlamentar que destituiu Dilma Rousseff do poder, encontram-se despreparadas para o enfrentamento.

Em segundo lugar, ela ocorre num quadro de excepcionalidade, em que as instituições da democracia representativa se encontram em crise, num arrefecimento de conjuntura que permite a implementação de ações do executivo e votações no congresso nacional desprovidas de respaldo popular e que recusam o diálogo com manifestações públicas e greves. Ademais, tais medidas recebem, em grande monta, o aval de um Poder Judiciário amoldado à ideia de conservação da ordem. 
Em terceiro lugar, a reforma contesta o paradigma protetivo dos trabalhadores, desenvolvido em razão de sua condição de hipossuficiência, de modo a colocar em risco a feição ontológica do Direito do Trabalho. Esse objetivo também é materializado por meio da dificuldade do acesso à Justiça do Trabalho, que passa a ser colocada em um simples papel de homologadora do negociado sobre o legislado. Tal processo, aliás, já vinha sendo sinalizado pela atuação do STF anteriormente à Reforma, ao se contrapor às decisões progressistas construídas historicamente pela Justiça do Trabalho.

A conjugação dos dois primeiros aspectos indica uma época em que se esgotou a possibilidade de algum tipo de "revolução passiva” - mesmo que periférica. No contexto atual, hegemonizado pela razão neoliberal, não só não há interesse das classes dominantes em qualquer negociação, como se busca desconstruir o que foi estabelecido outrora como fruto desse processo de "mudanças pelo alto", quando o país viveu o impulso para a industrialização sob a hegemonia do capital agroindustrial.

No presente momento, a lógica do capital financeiro e seu esquema de dominação se sobrepõem à dinâmica capitalista periférica do Brasil, gerando um processo de desindustrialização e desnacionalização. Assim, as parti-

$\stackrel{2}{\vec{F}}$ cularidades de um país dependente e suboriे dinado ao capital internacional se reforçam, colocando em risco a soberania nacional e promovendo retrocessos em seu desenvolvimento econômico, político e social.

A conjuntura presente, além de mostrar o esgotamento das reformas possíveis pelas $\dot{0}$ "revoluções passivas", as substituiu por uma “contrarrevolução pelo alto”. É a época das i contrarreformas, nas palavras do autor:

Não temos assim, na época em que estamos vivendo, o acolhimento de 'uma certa parte das exigências que vêm de baixo', que Gramsci considerava - como já vimos - uma característica essencial das revoluções passivas. Na época neoliberal, não há espaço para o aprofundamento dos direitos sociais, ainda que limitados, mas estamos diante da tenta- tiva aberta - infelizmente em grande parte bem sucedida - de eliminar tais direitos, de desconstruir e negar as reformas já conquistadas pelas classes subalternas durante a época de revolução passiva iniciada com o americanismo e levada a cabo no Welfare. As chamadas 'reformas' da previdência social, das leis de proteção ao trabalho, a privatização das empresas públicas etc. - 'reformas' que estão atualmente presentes na agenda política tanto dos países capitalistas centrais quanto dos periféricos (hoje elegantemente rebatizados como 'emergentes') - têm por objetivo a pura e simples restauração das condições próprias de um capitalismo 'selvagem', no qual devem vigorar sem freios as leis do mercado (Coutinho, C., 2012, p. 123).

O último aspecto essencial da contrarreforma trabalhista - a negação da hipossuficiência do trabalhador - ou seja, o não reconhecimento da sua condição vulnerável e subordinada reafirma a interpretação de Coutinho exposta acima. Implica retrocesso num padrão de organização e gestão capitalista do trabalho que já é historicamente predatório, com intensificação dos índices de exploração do trabalho, conduzindo a um quadro de amplificação da precarização.

Trata-se de tal ordem de modificações na legislação trabalhista brasileira, que não pode ser enquadrada como um conjunto de alterações periféricas e (ou) laterais no corpo normativo justrabalhista, senão em modificações que atingem a espinha dorsal do nosso quadro normativo e que alcançam, em diversos aspectos, o próprio paradigma constitucional de proteção ao trabalho. O que caracteriza o momento presente como momento de "crise e transição" do direito do trabalho (Delgado, 2018) é precisamente a natureza das modificações empreendidas no conjunto normativo, as quais são aptas recusar premissas que fizeram o direito do trabalho se afirmar, no século passado, como um campo autônomo e distinto do direito civil (campo do direito apto a reger relações privadas entre sujeitos que se encontram em posição de igualdade).

No bojo da reforma trabalhista, três aspectos parecem estruturantes do novo paradigma 
instituído e, consequentemente, desestruturantes do paradigma anterior: a admissão da autonomia privada da vontade; a admissibilidade da negociação coletiva em prejuízo do trabalhador, ou seja, rebaixando o patamar assegurado pela legislação estatal; e a desestruturação da categoria do emprego, como categoria central do direito do trabalho e "passaporte" para a fruição do conjunto de direitos assegurados pela CLT.

Quando se afirma a radicalidade das disposições legais que passam a admitir que o trabalhador, individualmente, negocie com seu empregador, antes, durante ou até depois do término do contrato de trabalho, cuida-se de considerar que foi exatamente por negar a validade desse tipo de ajuste individual entre empregado e empregador que o direito do trabalho afirmou sua existência. Foi denunciando a insuficiência da ideia de igualdade formal entre os sujeitos e considerando a desigualdade material profunda que tornava assimétricas as relações de trabalho, que o direito do trabalho se destacou do campo do direito civil para afirmar um campo normativo autônomo, regido pelo princípio da proteção ao hipossuficiente, que invalidaria declarações de vontade (adesões, consentimentos, acordos ou ratificações de contratos) dos trabalhadores que implicassem renúncia a direitos já assegurados pela legislação ou que os prejudicassem em relação a esse patamar.

Desse modo, quando a Lei $n^{\circ}$ 13.467/2017 passa a permitir ao empregado "escolher" a forma de contratação, negociar individualmente com o empregador sobre o banco de horas ou outros ajustes de compensação de jornada, negociar sobre a forma de extinção do seu contrato de trabalho, ou mesmo realizar acordos extrajudiciais a respeito dos haveres trabalhistas, submetidos à mera homologação judicial, bem como quando dispensa a presença do sindicato no momento da assinatura do termo de rescisão do contrato de trabalho, está a deixar de considerar, precisamente, esse conjunto de contingenciamentos e desigualdades que marcaram a razão de existir do Direito do Trabalho em outros momentos históricos.
Nessa mesma linha se dá a validação da negociação coletiva em prejuízo do trabalhador. Admissível pela Constituição Federal apenas em pontos específicos e excepcionais (compensação de jornada e redução salarial, conforme Art. $7^{\circ}$, IV, XIII e XIV, da CF/88), a nova legislação caminha na linha da modificação da função das negociações coletivas já reivindicada pela agenda neoliberal - que deixa de ser garantir direitos para ser garantir empregos, como observa Silva (2008) - passando a admitir um largo rol de situações em que os sindicatos podem acordar padrões inferiores aos legais, notadamente em matérias atinentes à saúde e segurança dos trabalhadores, como é o caso da redução do intervalo para repouso e alimentação de uma hora para trinta minutos e da autorização para labor extraordinário em atividade insalubre, independentemente de laudo técnico.

Nessa esteira, além do pernicioso papel de responsabilizar a capacidade de renúncia do movimento sindical pelo nível de emprego da categoria, num cenário de crise em que os ganhos reais, em mesas de negociação, já vinham minguando, a nova legislação fragiliza o paradigma da legislação trabalhista como estatuto universal de direitos dos trabalhadores empregados, passando a aprofundar o desnivelamento por categorias profissionais.

Ao mesmo tempo, privilegia-se, por meio da nova redação do art. 620 da CLT, a descentralização das negociações coletivas, com atribuição de mais valor aos acordos coletivos (celebrados entre sindicato dos trabalhadores e cada empresa, abrangendo apenas os empregados daquela empresa) do que às convenções coletivas (celebradas entre sindicato dos trabalhadores e sindicato patronal, abrangendo toda a categoria, e, portanto, tendencialmente mais robustas), ainda que isso implique a prevalência da norma menos favorável aos empregados.

Esse cenário é agravado por tratar-se de alteração legislativa que, por um lado, atribui altos níveis de responsabilidade ao movimento sindical, e, por outro, fragilizou consideravel- 
mente tais instituições com o fim da obrigatoriedade da contribuição sindical, sem mediação ou transição, o que implicou uma queda da ordem $88 \%$ da arrecadação sindical no ano de 2018. Esse contingenciamento financeiro foi recentemente acentuado pela Medida Provisória $\mathrm{n}^{0} 873 / 2019$, por meio da qual o Governo Bolsonaro burocratiza a forma de recolhimento e consentimento dos trabalhadores em relação à contribuição sindical, dificultando, assim, ainda mais, a arrecadação de contribuições pelos sindicatos.

Vale registrar que, das mais de 30 ações de controle de constitucionalidade ajuizadas contra a reforma trabalhista, as que versavam sobre o fim da obrigatoriedade da contribuição sindical foram reunidas e julgadas, por primeiro, pelo STF. Numa decisão por maioria, a Corte Constitucional brasileira fez prevalecer o texto da reforma, maximizando, também, numa linha de argumentação neoliberal, a liberdade individual dos trabalhadores, em detrimento dos debates constitucionais sobre os demais pilares da nossa estrutura sindical, notadamente a persistência da unicidade sindical (imposição do sindicato único por categoria na base territorial do município) e a persistência da obrigatoriedade de o sindicato representar indistintamente os sindicalizados e os não sin-

$\stackrel{7}{7}$ dicalizados da categoria respectiva. Assim, a reforma trabalhista se afirma como agenda que atravessa a conjuntura específica do parlamento brasileiro e encontra respaldo também nos demais poderes do Estado.

Por fim, como terceiro aspecto desestruturante introduzido pela reforma trabalhista, $\stackrel{\dot{0}}{0}$ importa frisar a desestabilização jurídica da ¿ categoria do emprego. Se é verdade que as di๙ vi versas formas de flexibilização do direito do trabalho e precarização do trabalho envolveram o recurso a formas de contratação heterogêneas, que refugavam o estatuto do emprego, por ser ele mais benéfico ao trabalhador, é possível dizer que, com a reforma trabalhista, a heterogeneidade das formas de contratação avança sobre a figura dos próprios emprega- dos, na medida em que se admitem, dentro da contratação empregatícia, subcategorias de empregados mais vulneráveis em termos de direitos: o contrato de emprego intermitente, a terceirização de atividade-fim e o contrato de trabalho do empregado "hipersuficiente" são exemplos dessa subcategorização do próprio emprego formal, com criação de subgrupos que passam a acessar menos direitos.

Além da figura bizarra do empregado intermitente, contratado sem previsão de jornada e de remuneração, que fica à disposição do empregador para recrutá-lo quando sua atividade econômica demandar, sem remunerar a disponibilidade do empregado, e, assim, transferindo o risco das oscilações da atividade empresarial à própria subsistência do trabalhador, a nova legislação ainda relativizou a ideia de vulnerabilidade do empregado em função da faixa salarial por ele ocupada e da sua formação escolar. Desse modo, passou-se a reconhecer como "hipersuficiente" e, portanto, apto a negociar as mesmas temáticas que o sindicato pode negociar (inclusive em prejuízo) diretamente com o empregador aquele trabalhador que recebe remuneração superior ao dobro do teto da Previdência Social (o que, hoje, equivale a cerca de onze mil reais) e que possui nível superior completo. Ainda, a Lei 13.467/2017 institucionalizou a possibilidade do teletrabalho, no bojo da relação de emprego, sem o controle de jornada e o consequente pagamento de horas extraordinárias e demais direitos tutelares dos limites da jornada de trabalho.

Através dessas modalidades precárias de trabalho, agora legalizadas, especialmente o trabalho intermitente, a reforma trabalhista implode com a garantia do salário mínimo, conquista importante e fundamental dos trabalhadores, abrindo margem para um processo de pauperização ainda mais significativo da classe trabalhadora.

Outro aspecto importante da reforma trabalhista é a restrição da possibilidade de a Justiça do Trabalho anular acordos desfavoráveis aos trabalhadores, como destacam Araújo, 
Dutra e Jesus (2017). Houve também a desconstrução do acúmulo histórico da Justiça do Trabalho, por meio da negação, pela via legal, de um conjunto de jurisprudências do TST (Araújo; Dutra; Jesus, 2017).

Ademais, a reforma dificultou o acesso à justiça, uma vez que abriu possibilidade de responsabilizar os trabalhadores pelos custos do processo (honorários, perícias, etc.), bem como ampliou as possibilidades de multa ao chamado "litigante de má-fé", instituindo ainda custas judiciais ao trabalhador que faltar à audiência. Como efeito dessa medida, conforme o TST, durante o ano de 2018, o número de novas reclamações abertas nas varas do trabalho (1.742.507 processos novos) caiu 46\%, se comparado com o mesmo período de 2017 (2.648.463 processos novos) (Brasil, 2017d).

\section{A TERCEIRIZAÇÃO COMO REGRA: serão todos os trabalhadores tercei- rizados?}

Para além desse amplo rol de "novidades”, que, em uma perspectiva social, representam retrocesso de um padrão de desenvolvimento, uma das grandes vitórias da bancada patronal certamente foi a liberação da terceirização de forma irrestrita.

Primeiro, por meio da Lei no ${ }^{\circ}$ 13.429/2017, de modo mais tímido, e, em seguida, por meio da Lei $\mathrm{n}^{0}$ 13.467/2017, de modo indene de dúvidas, admitiu-se a terceirização de toda e qualquer atividade empresarial, mediante mera responsabilidade subsidiária do tomador de serviços. Derrogou-se, assim, o marco regulatório da Súmula $\mathrm{n}^{\circ} 331$ do Tribunal Superior do Trabalho, que prevaleceu durante mais de duas décadas estabelecendo a impossibilidade de terceirização das atividades-fim das empresas, ao passo que admitia a terceirização das chamadas atividades-meio.

Isso foi feito suplantando-se todos os debates acumulados em torno do Projeto de Lei $\mathrm{n}^{\mathrm{0}} 4.330$, que já havia, inclusive, sido aprova- do na Câmara dos Deputados em 2015 e que pendia de aprovação do Senado, por meio de um projeto de lei que fora aprovado na Câmara dos deputados nos idos de 2001, ainda ao final do Governo FHC.

A normatividade posta não enfrentou questões cruciais da terceirização de atividade-fim, como a questão da sindicalização e das fraudes contratuais, estabelecendo, com cinismo, que "poderá" ser pago salário equitativo aos dos empregados da empresa tomadora de serviços. Num jogo concertado dos poderes da república, em agosto de 2018, o STF jogou a pá de cal sobre a questão, ao julgar a ADPF no 324. No julgamento da referida ação, ajuizada pela Associação Brasileira do Agronegócio, o qual foi combinado com o provimento ao Recurso Extraordinário (RE) $\mathrm{n}^{\circ}$ 958.252, da Empresa Cenibra, de Minas Gerais, com repercussão geral, o STF terminou por estabelecer a tese de que "É lícita a terceirização ou qualquer outra forma de divisão do trabalho [sic] entre pessoas jurídicas distintas, independentemente do objeto social das empresas envolvidas, mantida a responsabilidade subsidiária das empresas contratantes" (Brasil, 2018b).

Cabe destacar que essa manifestação judicial não foi feita sobre o texto da reforma trabalhista, mas sim sobre a Súmula $\mathrm{n}^{0} 331$ do TST, o que significa dizer que o STF entendeu que, mesmo antes da Reforma Trabalhista, já era possível terceirizar atividade-fim, e, assim, também antecipou um entendimento sobre a constitucionalidade do texto da reforma no que toca à terceirização.

A Lei 13.429 de 2017, além de alterar a legislação sobre trabalho temporário, redefinindo o tempo de contrato (de 90 para 180 dias), corroborou a possibilidade da terceirização em todas as atividades da empresa, através de "Empresa prestadora de serviços a terceiros", definida como "pessoa jurídica de direito privado destinada a prestar à contratante serviços determinados e específicos" (Brasil, 2017a).

A Lei 13.467 de 13 de julho de 2017 complementou a anterior lei da terceirização e 
colocou por terra o Enunciado 331, que proibia terceirizar a atividade-fim. O Art. $4^{\circ} \mathrm{A}$ - afirma:

Considera-se prestação de serviços a terceiros a transferência feita pela contratante da execução de quaisquer de suas atividades, inclusive sua atividade principal, à pessoa jurídica de direito privado prestadora de serviços que possua capacidade econômica compatível com a sua execução (Brasil, 2017b).

De acordo com as análises de pesquisadores do campo do direito do trabalho, essa nova regulamentação da terceirização fere frontalmente os princípios que regem a relação de emprego e em torno dos quais se erigia o sistema de proteção trabalhista pátrio. Segundo Sayonara Grillo C. Silva (2018, p. 5-6):

A institucionalização de um modo jurídico de organização contratual do trabalho alheio e subordinado por meio da contratação empresarial entre duas pessoas jurídicas para o repasse de quaisquer atividades da contratante para a contratada, admitindo-se a utilização plena dos meios de produção, estabelecimentos e equipamentos pela contratada (inclusive com o que Márcio Tulio Viana denomina no Brasil de terceirização interna) tem o potencial de promover profundas alterações no mercado de trabalho brasileiro, inclusive com o afastamento da regulação deste emprego da arena das instituições do direito do trabalho, diminuindo a incidência da negociação coletiva, da organização sindical e de outros institutos coletivos, e das garantias materiais e processuais ao crédito trabalhista, sem falar de outros direitos e do próprio direito do trabalho.

A relação entre a reforma e a terceirização vai mais além do que está formalmente definido no artigo 4 e em seus parágrafos, que liberam a terceirização para todas as atividades. Isso porque se compreende que a terceirização $\stackrel{\infty}{\infty}$ hoje, no Brasil, antecipa o que a "Reforma Tra¿ balhista” está legalizando para todos os trabaసิ lhadores: a precarização como regra.

ô Pesquisas já vinham apontando para o fato de que, por meio da sequência de violações de direitos que a terceirização costuma engendrar - correspondendo à "rarefação" dos direitos constitucionais trabalhistas, na lição de Gabriela Delgado e Helder Amorim (2014) -, o trabalhador terceirizado já enfrentava, na prática, um cenário de precarização tão aprofundando que equivalia a um processo de regulação do trabalho marginal e estranho àquele desenhado pela normatividade jurídica, o qual não lograva ser ajustado sequer mediante a atuação das instituições públicas de regulação do trabalho, como revelou a pesquisa feita por Dutra (2018) com operadoras de teleatendimento em Salvador.

Outros estudos acadêmicos e de instituições sindicais convergem no sentido de constatar a indissociabilidade entre terceirização e precarização do trabalho, demonstrando tanto o esvaziamento do valor dos direitos trabalhistas quanto o seu efetivo descumprimento associado à circunstância terceirizada. Nesse sentido, pesquisa empreendida pelo Departamento Intersindical de Estatística e Estudos Socioeconômicos (DIEESE) demonstra, de um lado, a desigualdade salarial, pois terceirizados chegam a ganhar $30 \%$ menos que os contratados diretamente, e, de outro, o desrespeito à duração máxima do trabalho, com a evidência de que as jornadas dos trabalhadores terceirizados superam, em média, em três horas as dos demais trabalhadores (CUT; DIEESE, 2014).

O perecimento das normas de saúde e segurança, entre os trabalhadores terceirizados, é demonstrado por meio de indicadores de acidentes de trabalho e mortes, como revela o caso dos petroleiros, em que os terceirizados mortos representam 90\% do total. Já na construção civil, o número de mortes dos terceirizados é de 2,3 a 4,9 vezes maior do que a média de acidentes fatais em todo o mercado de trabalho. Também se extrai tal conclusão do alto grau de adoecimento dos trabalhadores de call centers, por LER/DORT (Antunes; Druck, 2013; Coutinho, G., 2015; Druck; Filgueiras, 2014).

Pesquisa empreendida por Vitor Filgueiras revela uma dupla causalidade relacionando o trabalho terceirizado e a acidentalidade: por um lado, os trabalhadores terceirizados são mais vulneráveis a acidentes que trabalhadores contratados diretamente (circunstância potencialmente relacionada à deficiência de 
treinamento, ao equipamento e à maior rotatividade desses empregados) e, por outro, as empresas terceirizam prioritariamente aquelas atividades que apresentam maiores riscos ocupacionais, como forma de "externalização do risco” (Filgueiras; Cavalcante, 2015).

Também entre os trabalhadores terceirizados em atividades-meio e no serviço público, observa-se o mesmo padrão de desrespeito a direitos trabalhistas: é o caso dos trabalhadores terceirizados de limpeza da UFBA. Pesquisa realizada por Druck e colaboradores no ano de 2018, revelou não apenas um crescimento desproporcional do número de trabalhadores terceirizados em relação ao quadro de servidores públicos ocupantes do cargo de técnicos-administrativos da Universidade, como também registrou um cenário de profundo desrespeito aos direitos dos terceirizados, que chegam a ficar 10 anos sem férias, por conta da troca de empresas que não completam um ano prestando serviços e são substituídas sem pagar a seus empregados (DRUCK et al., 2018).

É também esse o caso das redes de subcontratação no complexo automotivo do Nordeste, em que, na ponta do processo, há trabalhadores prestando serviços sem carteira assinada e por “empreitada” (Druck; Filgueiras, 2014).

Há, também, o relevante cruzamento dos dados concernentes à terceirização e essa que é a fronteira extrema da exploração do trabalho em desrespeito aos limites regulatórios do direito do trabalho: a condição de trabalho análogo ao escravo. Pesquisas apontam que, do total de trabalhadores resgatados entre 2013 e 2015, $81 \%$, eram terceirizados (Filgueiras; Cavalcante, 2015), demonstrando que o afastamento do trabalhador em relação à fonte tomadora dos seus serviços contribui para o processo de degradação de suas condições de trabalho.

Diante desse panorama, se, por um lado, é verdade que, para os trabalhadores que já eram terceirizados, se observa um pequeno impacto das modificações legislativas, uma vez que eles efetivamente já não alcançavam o conteúdo de muitos dos direitos que foram flexibilizados e (ou) extintos, por outro lado, a circunstância que se observa é a tendência de que aqueles que não experimentavam a condição de trabalho terceirizado passem a vivenciar a mesma intensidade da precarização incidente aos casos de terceirização.

Ter a liberdade de contratar trabalhadores autônomos, usar o trabalho intermitente, transformando o empregado num "empreendedor de si mesmo", por tempo parcial, por teletrabalho, bem como todas as formas precárias de trabalho com nuances e vulnerabilidades intencionalmente ocultadas pela nova legislação, permite aos empresários desresponsabilizar-se pelos custos de direitos do trabalho. É exatamente isso o que já acontece com a terceirização.

Para aqueles que serão contratados através do emprego direto com o tomador de serviços, se impõem maiores e mais flexíveis jornadas de trabalho, menor tempo de descanso ou intervalo para almoço, parcelamento das férias, possibilidade de redução salarial, mitigação das normas de proteção à saúde e segurança do trabalhador (que passam, em grande medida, a ser também negociadas), entre outras medidas desprotetivas. Tais condições são aquelas já encontradas e reveladas pelas pesquisas sobre terceirização no Brasil.

Assim é que, após a promulgação da Lei 13.467/2017, velhas e novas formas de contratação precárias são validadas ou instituídas, tornando a precarização a regra, situação antecipada e vivida pelos trabalhadores terceirizados.

\section{ALGUNS RESULTADOS SOBRE A DINÂMICA DO TRABALHO E DO EMPREGO}

Passado um ano após a entrada em vigor da reforma trabalhista, os primeiros efeitos revelam uma acentuação do processo de precarização do trabalho que podem ser evidenciados, dentre outros indicadores, pelo crescimento da vulnerabilidade das formas de inserção e das desigualdades sociais. 
De início, é importante observar que a principal promessa veiculada pelos idealizadores da reforma trabalhista - a criação de empregos - não se cumpriu. Se, em outubro de 2017, o cenário era de 12,740 milhões de desempregados, 12,2\% (Filgueiras, 2019), e uma taxa de desocupação de 12,8\% (Bonfim, 2018), após um ano da reforma trabalhista, o que se constata é a persistência de um montante de 12,351 milhões de desempregados em outubro de 2018, 11,7\%. Em números absolutos, tem-se 12,669 milhões (12\%) em 2019 (Filgueiras, 2019). Após um período de leve recuperação, relacionada ao aumento do PIB, o desemprego volta a crescer, afastando-se drasticamente do período anterior, em que se alcançava um saldo de dois milhões de emprego por ano.

Também não se pode perder de vista que o percentual de subempregados aumentou de 23,8\% (em outubro de 2017) para 24,1\% (em outubro de 2018), caracterizando condições de trabalho que, por sua remuneração ou carga horária, são insuficientes para a mantença do trabalhador e de sua família (Filgueiras, 2019). Por outro lado, a taxa de desalento (pessoas que, embora não empregadas, desistiram de procurar emprego) foi elevada de 4,278 milhões para 4,776 milhões após a reforma trabalhista, num incremento de 500 mil pessoas nessa situação de $\stackrel{乛}{\sigma}$ vulnerabilidade, dado que compõe o índice de iे desemprego (Bonfim, 2018).

O cenário de pós-reforma trabalhista também marca o mercado de trabalho brasileiro com um número recorde de informalidade: 11,5 milhões de trabalhadores prestando serviços por conta própria ou sem carteira de trabalho, contra os 10,979 verificados em novembro de 2017 (Bonfim, 2018).

Ainda, cabe observar que, das vagas de emprego geradas, apenas $12 \%$ correspondem aos contratos de trabalho intermitentes, tão alardeados como modo de formalização dos bicos. Esses contratos se concentraram em áreas já caracterizadas por esse tipo de engajamento, como construção civil, comércio e serviços de garçons. Interessante é observar que, ao con- trário do que se propagou, a maior parte dos trabalhadores contratados de modo intermitente não conseguiu manter mais de um contrato concomitantemente: os dados revelam que, dos 35.930 empregos intermitentes criados, apenas 693 trabalhadores tinham mais de um contrato ativo simultaneamente (Bonfim, 2018).

Dados do extinto Ministério do Trabalho e Emprego informam que a queda da arrecadação sindical, durante o ano de 2018, foi da ordem de 88\% (Gavras, 2018). Também se observou, no primeiro ano da reforma, uma queda do número de acordos e convenções coletivas de trabalho da ordem de $28,6 \%$, a revelar uma inibição da atividade sindical e da própria disposição negocial dos empregadores (DIEESE, 2018). Por fim, dados do CESIT/Unicamp revelam que, entre novembro de 2017 e novembro de 2018, observou-se uma queda de 30 bilhões da arrecadação previdenciária, como consequência do desaquecimento do mercado de trabalho, do aumento da informalidade e da ampliação das subcontratações (Rede Brasil Atual, 2018).

A reforma trabalhista aprofundou o processo de mercantilização da força de trabalho, colocando em novas bases a vulnerabilidade estrutural existente no mercado de trabalho brasileiro, em que um dos traços mais marcantes é a inserção precária, sem nenhum tipo de proteção social e um alto número de desempregados.

Os dados acerca dos primeiros efeitos da reforma trabalhista sobre a dinâmica do trabalho e emprego no Brasil corroboram as pesquisas realizadas em outros países sobre a temática. Em 2015, a Organização Internacional do Trabalho (OIT) publicou um estudo sobre os impactos das reformas trabalhistas no nível do emprego (Adascalitei; Morano, 2015). Os autores analisaram a relação entre proteção ao trabalho, desemprego, taxa de ocupação e participação. Numa primeira base de dados, foram incluídos 63 países, nos anos de 1993 a 2013; e, numa segunda investigação, 111 países, no período de 2008 a 2014. As conclusões do estudo mostram que, em termos estatísticos, não se comprova a relação entre rigidez da legislação trabalhista e nível de emprego. 
Há evidências publicadas em artigos e pela imprensa que, naqueles países em que houve reformas trabalhistas austeras, não só o desemprego não diminuiu como as formas de inserção precárias têm levado milhões de trabalhadores, jovens principalmente, a uma situação de desespero diante da falta de perspectivas de futuro e de sobrevivência digna. É a chamada "geração desencantada". É o caso mais destacado da Espanha, com altos índices de desemprego (18\%) e $43 \%$ entre os jovens, desde a reforma trabalhista feita em 2012. A mudança legislativa não estancou o desemprego e ainda criou um enorme rebaixamento salarial, inclusive para postos de trabalho mais qualificados, criando uma instabilidade permanente. E é nessa reforma trabalhista que os especialistas do Governo Temer disseram ter se espelhado para propor a "reforma" no Brasil.

\section{CONSIDERAÇÕES FINAIS}

No contexto de instabilidade democrática e retirada de direitos sociais, a atuação dos sindicatos, órgãos da justiça do trabalho e redes acadêmicas constituem focos de resistência e denúncia dos efeitos da reforma.

No Brasil, há um dissenso entre juízes na interpretação da norma, revelando que a Lei $13.467 / 2017$, ao contrário do que foi prometido, resultou em uma imensa insegurança jurídica. Um indicador desse dissenso em torno da contrarreforma trabalhista é o fato de juízes do trabalho, reunidos no XIX Congresso Nacional dos Magistrados da Justiça do Trabalho da Associação Nacional dos Magistrados da Justiça do Trabalho (ANAMATRA), em maio de 2018, discutirem e aprovarem em plenário um conjunto de teses que afirmam a inconstitucionalidade da Lei 13.467/2017, o desrespeito aos tratados internacionais, a impossibilidade de sua aplicação retroativa e a invalidade das disposições que implicam tolher os Juízes do Trabalho de sua liberdade de julgar e de decidir com base na Constituição Brasileira e afastando as incongruências do texto da Lei.

A "Carta de Belo Horizonte", aprovada por aclamação, sintetiza as principais teses aprovadas:

[...] Reafirmam a absoluta necessidade de respeito à independência da Magistratura, à autonomia do Poder Judiciário Trabalhista e à dignidade da autoridade judiciária, respeitada sempre, no livre exercício da função jurisdicional em sua forma plena, a prerrogativa de aplicação do Direito mediante a interpretação da norma em conjunto com as regras e princípios constitucionais e suas hierarquias, assim como em concordância harmônica com os tratados e convenções internacionais de que o Brasil seja parte.

Declaram que a independência técnica do Juiz é garantia de cidadania e do Estado democrático de Direito, não podendo ser utilizada para barganhar a existência, a subsistência ou a persistência da Justiça do Trabalho.

Afirmam a importância e necessidade de existência da Justiça do Trabalho no Brasil como órgão do Poder Judiciário essencial ao funcionamento do sistema de Justiça e para a pacificação dos conflitos, reequilibrando as desigualdades sociais existentes, a exemplo de como ocorre em outros países, inclusive da Europa, como no caso da Alemanha [...]

Alertam que a Reforma Trabalhista trouxe visível precarização das relações de trabalho, conforme índices oficiais já divulgados, referentes ao aumento de desemprego e da informalidade, sendo que a queda do número de ações trabalhistas trouxe consigo a diminuição da arrecadação de custas e contribuições previdenciárias pela Justiça Laboral, o que adensa as teses de extinção desse ramo especializado do Poder Judiciário (ANAMATRA, 2018b).

Registra-se que o movimento sindical brasileiro, apesar da realização das greves gerais nos dias 28 de abril e 30 de junho de 2017 e de outras manifestações, não conseguiu barrar a reforma trabalhista face à correlação de forças desfavorável no Congresso Nacional. Após a aprovação da Lei 13.467/2017, parte do sindicalismo passou a negociar com o próprio governo a edição de uma medida provisória, que foi posteriormente publicada e cuja validade expirou, sem conversão em lei (MP $n^{\circ}$ 808/2017), conforme já foi mencionado.

Como pontos de resistência, também vale destacar a decisão do Comitê de Aplica- 
ção de Normas Internacionais, durante a $107^{\mathrm{a}}$ Conferência da Organização Internacional do Trabalho (OIT), que considerou que a Lei 13.467/2017 contém graves violações a normas de proteção internacional, e incluiu o Brasil na lista dos 24 casos mais graves de desrespeito ao Direito Internacional do Trabalho (ANAMATRA, 2018a).

Entre as ações de contestação, cabe registrar ainda que existem mais de 30 Ações Diretas de Inconstitucionalidade (ADI) da Lei da reforma trabalhista encaminhadas ao Supremo Tribunal Federal (STF).

Ressalta-se a ADI $5766,{ }^{2}$ proposta pela Procuradoria Geral da República, referente aos obstáculos criados para os trabalhadores acessarem o Poder Judiciário, uma vez que a Lei 13.647/17 institui que os trabalhadores, mesmo que sejam beneficiários de Justiça Gratuita,

[...] quando sucumbentes no pedido objeto de perícia serão responsabilizados pelos honorários periciais, estabelecendo, inclusive, que esses honorários possam ser deduzidos do crédito trabalhista reconhecido na sentença. Na mesma linha, prevê a hipótese de sucumbência recíproca e condenação em honorários de advogado da parte contrária, também com previsão de dedução do crédito reconhecido judicialmente (Biavaschi et al., 2017, p. 9).

No âmbito do Tribunal Superior do Trabalho (TST), foi editada a Instrução Nor. mativa $\mathrm{n}^{\mathrm{o}} 41 / 2018$, em junho de 2018, pre$\stackrel{8}{*}$ vendo que os novos dispositivos sobre direito material do trabalho somente seriam aplicáveis aos contratos firmados após a reforma, o que demarca uma posição divergente daquela outrora constante na já caducada MP $n^{\circ}$ 808/2017. Entretanto, quanto aos dispositivos processuais, o Tribunal Superior do Trabalho હ̃ entendeu que "aplicação das novas normas é $\therefore$ imediata, sem atingir, no entanto, situações iniciadas ou consolidadas antes das alterações. Assim, a maioria das alterações proces-

${ }^{2}$ O STF havia iniciado o exame dessa ADI, com dois votos colhidos em sentidos divergentes, mas o julgamento foi interrompido em virtude de pedido de vista regimental, estando suspenso o julgamento até o momento do fechamento deste artigo. suais não se aplica aos processos iniciados antes de 11/11/2017" (Brasil, 2018a).

Entre os temas tratados na Instrução Normativa $n^{0} 41 / 2018$, estão a prescrição intercorrente, os honorários periciais e sucumbenciais, a responsabilidade por dano processual, a aplicação de multa a testemunhas que prestarem informações falsas, o fim da exigência de que o preposto seja empregado e a condenação em razão de não comparecimento à audiência. O TST estabelece parâmetros para si e para as demais instâncias guardarem em relação a esses temas de aplicação imediata da reforma, minorando, assim, os efeitos da insegurança jurídica criada. Por outro lado, as discussões sobre a constitucionalidade dos dispositivos da reforma ainda estão passíveis de disputa naquela Corte, embora se observe uma modificação recente na composição do Tribunal.

Destaque-se que as pautas de interesse dos trabalhadores brasileiros amargaram derrota eleitoral, com ascensão de Jair Bolsonaro ao poder, o que representou, do ponto de vista econômico, a ascensão de um projeto de orientação ultraliberal. Entretanto, é de se destacar a expressiva votação, sobretudo no Nordeste, do candidato opositor, cuja principal plataforma de oposição ao candidato eleito consistia nas políticas de trabalho, renda e redistribuição.

Logo nos primeiros cem dias de governo, além da extinção do Ministério do Trabalho, de ameaças públicas de extinção da Justiça do Trabalho, deu-se o sintomático endurecimento da relação com o financiamento sindical, por meio da recém-editada Medida Provisória $n^{\circ} 873 / 2019$, que impõe um procedimento burocrático e pouco usual para o recolhimento da contribuição sindical (por meio de boleto individual remetido para a residência do trabalhador). Exigiu também que a realização da contribuição seja autorizada também individualmente pelos trabalhadores, em oposição ao mecanismo de autorização por assembleia ou por negociação coletiva que o movimento sindical vinha implementando desde a reforma. 
Ademais, a ofensiva do governo Bolsonaro se volta para aquilo que o seu antecessor não pôde concluir: a reforma previdenciária, que, na proposta atual, se radicaliza no sentido de instituir um regime de capitalização no país.

É verdade, por outro lado, que o próprio presidente da república tem encontrado dificuldades de compor com a base aliada para a aprovação do seu projeto de reforma da previdência, o que tem atrasado o processo.

Entretanto, observam-se inciativas como a elaboração de um novo Estatuto do Trabalho, fruto de um trabalho coletivo que reuniu parlamentares, juízes, auditores fiscais do trabalho, procuradores do trabalho, representantes sindicais, discutindo há nove meses, com a realização de 20 audiências públicas, organizadas através de uma subcomissão temporária da Comissão de Direitos Humanos e Legislação Participativa (CDH) do Senado.

Também é importante considerar a formação de grupos que reúnem acadêmicos, jurídicos e sindicalistas, que têm promovido debates, ações e formação de redes de acompanhamento dos efeitos da reforma trabalhista, a exemplo da Rede de Estudos e Monitoramento Interdisciplinar da Reforma Trabalhista (REMIR), criada em março de 2018, com o objetivo de mensurar os impactos da reforma trabalhista na dinâmica do trabalho e do emprego no Brasil.

Existem, ainda, iniciativas de setores do movimento sindical, como a proposição de uma campanha nacional pela revogação da Lei da Reforma Trabalhista e, mais recentemente, a chamada de manifestações nacionais contra a reforma da previdência, numa perspectiva de greve geral, que constituem indicações de que há resistências.

Por isso, a despeito da promulgação da Lei 13.467/2017, as lutas sociais e as disputas jurídicas em torno da reforma trabalhista podem conseguir barrar a efetividade dos dispositivos legais e, por isso, se pode afirmar que sua implementação consiste em cenário disputável, pois depende da capacidade de mobi- lização da classe trabalhadora brasileira num contexto de um governo de crise.

Recebido para publicação em 28 de março de 2019 Aceito em 31 de maio de 2019

\section{REFERÊNCIAS}

ADASCALITEI, D.; MORANO, C. P. Labour market reforms since the crisis: Drivers and consequences. ILO: research department working paper, n. 5, oct. 2015. Disponível em: http://www.ilo.org/global/research/publications/workingpapers/WCMS_414588/lang--en/index.htm. Acesso em: 24 set. 2017.

ANTUNES, R.; DRUCK, G. A terceirização como regra? Revista do Tribunal Superior do Trabalho, v. 79, p. 214231, 2013.

ARAÚJO, M. A. de; DUTRA, R. Q.; JESUS, S. C. S. de. Neoliberalismo e flexibilização da legislação trabalhista no Brasil e na França. Caderno CEAS, Salvador, n. 242, p. 558-581, set./dez. 2017. Disponível em: https:// cadernosdoceas.ucsal.br/index.php/cadernosdoceas/ article/view/401. Acesso em: 20 maio 2018.

ARTUR, K.; PESSANHA, E. Trabalhadores e agentes do direito na defesa do Direito do Trabalho. In: SEMINÁRIO INTERNACIONAL SOBRE TERCEIRIZAÇÃO LABORAL, 2018, Buenos Aires. Anais [...]. Buenos Aires: [S.n.], 2018.

ASSOCIAÇÃO NACIONAL DOS MAGISTRADOS DA JUSTIÇA DO TRABALHO (ANAMATRA). Reforma trabalhista: Brasil está na lista dos 24 casos mais graves que a OIT investigará por violação a normas internacionais do trabalho, maio 2018a. Disponível em: https://www. anamatra.org.br/imprensa/noticias/26543-reformatrabalhista-brasil-esta-na-lista-dos-24-casos-mais-gravesque-oit-investigara-por-violacao-a-normas-internacionaisdo-trabalho). Acesso em: 30 maio 2018.

ASSOCIAÇÃO NACIONAL DOS MAGISTRADOS DA JUSTIÇA DO TRABALHO (ANAMATRA). O futuro da magistratura do trabalho em debate. Jornal Anamatra, Belo Horizonte, 2018b. Disponível em: https:/www.anamatra. org.br/attachments/article/27003/Jorna\%20Especial\%20 19\%20Conamat.pdf. Acesso em: 15 ago. 2019. 21h 43min.

BIAVASCHI, M. et al. Os impactos de algumas reformas trabalhistas na regulação e nas instituições públicas que atuam no mundo do trabalho: experiências internacionais. Campinas: CESIT, 2017. (Parte 2). Disponível em: http://www.cesit.net. br/wp-content/uploads/2017/11/Texto-de-Discuss\%C3\%A3o2-Os-impactos-de-algumas-reformas-trabalhistas-naregula\%C3\%A7\%C3\%A3o-e-nas-institui\%C3\%A7\%C3\%B5esp\%C3\%BAblicas-1.pdf. Acesso em: 15 fev. 2017.

BONFIM, M. Nova CLT completa um ano. $1^{\circ}$ nov. 2018. In: UOL: o melhor conteúdo. Versão em português. São Paulo, 1996-2019. Disponível em: https://economia.uol.com.br/ reportagens-especiais/apos-um-ano-reforma-trabalhistanao-criou-empregos-prometidos-e-informalidade-cresceu/ index.htm\#nova-clt-completa-um-ano. Acesso em: 24 mar. 2019. 19h 21min.

BRAGA, R. A política do precariado: do populismo à hegemonia lulista. São Paulo: Boitempo, 2012.

BRASIL. Lei $n^{\circ}$ 6.019, de janeiro de 1974. Dispõe sobre o trabalho temporário nas empresas urbanas, e dá outras Providências. Brasília: Casa Civil, 1974.

BRASIL. Lei $n^{\circ}$ 13.429, de 31 de março de 2017. Altera dispositivos da Lei $n^{\circ} 6.019$, de 3 de janeiro de 1974, que dispõe sobre o trabalho temporário nas empresas urbanas 
e dá outras providências; e dispõe sobre as relações de trabalho na empresa de prestação de serviços a terceiros. Brasília: Casa Civil, 2017a.

BRASIL. Lei $n^{o}$ 13.467, de 13 de julho de 2017. Altera a consolidação das Leis do Trabalho (CLT), aprovada pelo Decreto-Lei $\mathrm{n}^{\circ} 5.452$, de $1^{\circ}$ de maio de 1943 , e as Leis nos 6.019, de 3 de janeiro de 1974, 8.036, de 11 de maio de 1990, e 8.212, de 24 de julho de 1991, a fim de adequar a legislação às novas relações de trabalho. Brasília: Casa Civil, 2017b.

BRASIL. Medida Provisória n. 808, de 14 de novembro de 2017. Brasília: Casa Civil, 2017c. Disponível em: http:// www.planalto.gov.br/ccivil 03/_ato2015-2018/2017/Mpv/ mpv808.htm. Acesso em: $2 \overline{0}$ dez. 2017.

BRASIL. Conselho Nacional de Justiça (CNJ). Justiça em números: 2017 (ano-base 2016). Brasília: CNJ, 2017d. Disponível em:https://www.cnj.jus.br/pesquisasjudiciarias/justicaemnumeros/2016-10-21-13-13-04/pjjustica-em-numeros. Acesso em: $1^{\circ}$ fev. 2018.

BRASIL. Tribunal Superior do Trabalho (TST). Primeiro ano da reforma trabalhista: efeitos. 2018a. Disponível em: http://www. tst.jus.br/noticias/-/asset publisher/89Dk/content/primeiroano-da-reforma-trabalhista-efeitos?inheritRedirect $=$ false. Acesso em: 24 mar. 2019. 19h 31min.

BRASIL. Supremo Tribunal Federal. Recurso extraordinário $n^{\circ}$ 958.252, de 31 ago. 2018. Brasília: Supremo Tribunal Federal, 2018b. Disponível em: http://stf.jus.br/portal/diarioJustica/verDiarioProcesso. a sp?numDj=180\&dataPublicacaoDj31/08/2018 \&incidente $=4952236 \&$ codCapitulo $=2 \&$ num Materia= 30\&codMateria=4. Acesso em: 24 mar. 2019.

CALIXTO, C. C. A narrativa jornalística e o ocultamento do trabalho como direito fundamental. 2013. $190 \mathrm{f}$. Dissertação (Mestrado em Direito) - Universidade de Brasília, Brasília, 2013.

CENTRAL ÚNICA DOS TRABALHADORES (CUT); DEPARTAMENTO INTERSINDICAL DE ESTATÍSTICA E ESTUDOS SOCIOECONÔMICOS (DIEESE). Terceirização e desenvolvimento: uma conta que não fecha: dossiê sobre o impacto da terceirização sobre os trabalhadores e propostas para garantir a igualdade de direitos. São Paulo: CUT, 2014.

CENTRO DE ESTUDOS SINDICAIS E DE ECONOMIA DO TRABALHO (CESIT). Dossiê Reforma Trabalhista no Brasil. Campinas: CESIT, 2017. Disponível em: http:// www.cesit.net.br/dossie-reforma-trabalhista/. Acesso em: 15 dez. 2017.

$\stackrel{7}{\rightarrow}$ CONFEDERAÇÃO NACIONAL DA INDÚSTRIA (CNI). 101

จ propostas para modernização trabalhista. Brasília: CNI,

$\circ$ 2012. Disponível em: http://www.portaldaindustria.com.

$\sum^{2}$ br/publicacoes/2013/2/101-propostas-para-modernizacaoo trabalhista/. Acesso em: 3 abr. 2013.

$\sum$ COUTINHO, C. N. A época neoliberal: revolução passiva in ou contra-reforma? Novos rumos, Marilia, v. 49, n. 1, p.117-126, 2012.

: COUTINHO, G. F. Terceirização: máquina de moer N gente trabalhadora: a inexorável relação entre a nova

2 merchandage e a degradação ambiental, as mortes e

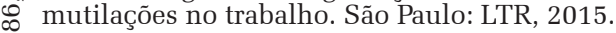

\& DARDOT, P.; LAVAL, C. A nova razão do mundo: ensaio ते sobre a sociedade neoliberal. São Paulo: Boitempo, 2016.

$>$ DELGADO, G. N.; AMORIM, H. Os limites constitucionais डิ da terceirização. São Paulo: LTr, 2014.

DELGADO, M. G. Curso de Direito do Trabalho. São Paulo: LTr, 2018

İ DEPARTAMENTO INTERSINDICAL DE ESTATÍSTICA E ي ESTUDOS SOCIOECONÔMICOS (DIEESE). Boletim de - Conjuntura, n. 17, dez. 2018. Disponível em: https://www.dieese. org.br/boletimdeconjuntura/2018/boletimConjuntura017.html. Acesso em: 24 mar. 2019. 19h 40min.
DRUCK, G. et al. A terceirização no serviço público: particularidades e implicações. In: CAMPOS, A. G. (Org.). Terceirização do trabalho no Brasil: novas e distintas perspectivas para o debate. Brasília: Ipea, 2018.

DRUCK, G.; FILGUEIRAS, V. A epidemia de terceirização e a responsabilidade do STF. Revista do TST, Brasília, v. 80, n. 3, p. 106-125, jul./set. 2014.

DUTRA, R. Trabalho, regulação e cidadania: a dialética da regulação social do trabalho. São Paulo: LTR, 2018.

FILGUEIRAS, V. Estado e direito do trabalho no Brasil: regulação do emprego entre 1988 e 2008. 2012. Tese (Doutorado) - Faculdade de Filosofia e Ciências Humanas, Universidade Federal da Bahia, Salvador, 2012.

FILGUEIRAS, Vitor Araújo. As promessas da reforma trabalhista: combate ao desemprego e redução da informalidade. In: KREIN, José Dari; OLIVEIRA, Roberto Véras de; FILGUEIRAS, Vitor Araújo (orgs). Reforma trabalhista no Brasil: promessas e realidade. Campinas, SP: Curt Nimuendajú, 2019.

FILGUEIRAS, V.; CAVALCANTE, S. Terceirizacão: debate conceitual e conjuntura política. Revista da ABET, v. 14, n. 1, jan./jun. 2015.

FRENCH, J. D. Afogados em leis: a CLT e a cultura política dos trabalhadores brasileiros. Tradução: Paulo Fontes. São Paulo: Fundação Perseu Abramo, 2002.

GAVRAS, D. Seis meses após reforma trabalhista, arrecadação de sindicatos desaba $88 \%$. 4 jun. 2018. In: UOL: o melhor conteúdo. Versão em português. São Paulo, 1996-2019. Disponível em: https://economia.uol.com.br/ noticias/estadao-conteudo/2018/06/04/seis-meses-aposreforma-trabalhista-arrecadacao-de-sindicatos-desaba-88. htm. Acesso em: 24 mar. 2019. 19h 43min.

HARVEY, D. A condição pós-moderna. São Paulo: Loyola, 1992

HARVEY, D. O novo Imperialismo. 2. ed. São Paulo: Loyola, 2006.

ILO. World employment and social outlook 2015: the changing nature of jobs/ International Labour Office. Geneva: ILO, 2015.

MIRANDA, A. G. C. O Direito do Trabalho na Ditadura civilmilitar. 2016. Disponível em: http://www.conteudojuridico. com.br/artigo,o-direito-do-trabalho-na-ditadura-civilmilitar,56747.html. Acesso em: 27 dez. 2018.

REDE BRASIL ATUAL. Trabalhadores são prejudicados um ano após a 'reforma' trabalhista. $1^{\circ}$ nov. 2018. Disponível em: https://www.redebrasilatual.com.br/trabalho/2018/11/ trabalhadores-sao-prejudicados-um-ano-apos-a-reformatrabalhista. Acesso em: 24 mar. 2019. 19h 23min.

SANTOS, W. G. dos. A democracia impedida: o Brasil no século XXI. Rio de Janeiro: Editora FGV, 2017.

SILVA, S. G. C. L. Relações coletivas de trabalho. São Paulo: LTr, 2008.

SILVA, S. G. C. L. da. Terceirização e Reforma Trabalhista no Brasil: o debate nas arenas jurisdicionais. In: SEMINÁRIO INTERNACIONAL SOBRE TERCEIRIZAÇ̃̃O LABORAL. Anais [...] Buenos Aires: [S.n.], 2018.

SOUTO MAIOR, J. L. Efeitos negativos do golpe de 64 nos direitos trabalhistas. 2014. Disponível em: https:// blogdaboitempo.com.br/dossies-tematicos/o-que-restado-golpe-de-64/os-50-e-tantos-anos-dos-golpes-contra-aclasse-trabalhadora-por-jorge-luiz-souto-maior/12-efeitosnegativos-do-golpe-de-64-nos-direitos-trabalhistas/. Acesso em: 27 dez. 2018.

VALIM, R. Estado de exceção: a forma jurídica do neoliberalismo. São Paulo: Contracorrente, 2017.

VIANNA, L. W. Liberalismo e sindicato no Brasil. 4. ed. Belo Horizonte: Ed. UFMG, 1999. 


\section{THE LABOR COUNTER-REFORM: outsourcing and precarization as a rule}

\author{
Renata Dutra \\ Graça Druck \\ Selma Cristina Silva
}

The objective of this article is to discuss some of the main elements of the so-called "labor reform" in Brazil, situating it in the current conjuncture of the Brazilian reality in the context of globalized and flexible capitalism under neoliberal hegemony. It seeks to answer the following questions: i) why was it possible to approve this counter-reform at this time, after more than 30 years of attempts by the business community to end CLT? ii) What is the essence of this counter-reform? iii) What is the relationship between outsourcing and the changes in the new legislation? iv) What are the main changes and which spaces and areas do they affect? v) What are the resistances and perspectives manifested by the most different social subjects to the new legislation?

KeY-words: Brazilian labor counter-reform. Outsourcing. Precarization of the work. Act 13.467. Resistances.

\section{LA CONTRE-RÉFORME NÉOLIBÉRALE ET LA SOUS-TRAITANCE: la précarisation en règle générale}

\author{
Renata Dutra \\ Graça Druck \\ Selma Cristina Silva
}

Le but de cet article est de discuter des principaux éléments de l'essence de la contre-réforme de la législation du travail au Brésil, en la situant dans la conjoncture actuelle de la réalité brésilienne, dans le contexte d'un capitalisme globalisé et flexible, sous hégémonie néolibérale. On cherche à répondre aux questions suivantes: i) Pourquoi était-il possible d'approuver cette contre-réforme à ce moment-là, après plus de 30 ans de tentatives de la part des entrepreneurs de mettre fin au CLT? ii) Quelle est l'essence de cette contre-réforme? iii) Quelle est la relation entre la sous-traitance et les modifications de la nouvelle législation? iv) Quels sont les principaux changements et quels espaces et groupes sont affectés par ces changements? v) Quelles sont les résistances et les points de vue manifestés par les plus différents sujets sociaux confrontés à la nouvelle législation?

Mots-CLÉs: Réforme de la législation du travail au Brésil. Sous-traitance. Précarisation du travail. Loi 13.467. Résistances. 
